\title{
La evaluación cualitativa
}

Ian Shaw

Paidós., Barcelona., 2003., 320 págs.

\section{DATOS DEL AUTOR}

Ian Shaw es profesor investigador en la Universidad de Cardiff, Gran Bretaña. Sus intereses profesionales se centran en el desarrollo de teorías sobre la evaluación de la metodología cualitativa, el trabajo social y la Sociología, además del desarrollo de software como facilitador del aprendizaje. Es profesor de métodos de investigación y trabajo social. Autor de Evaluation and Social Work Practice; Qualitative Social Work Research; Prostitution Aldershot: Ashgate; Social Work, entre otras obras.

\section{CONTENIDO}

En los últimos años, el ámbito del estudio pedagógico se ha visto inundado por una gran cantidad de textos en torno a la investigación cualitativa, como un paradigma de investigación que busca contrarrestar la reducción de los procesos educativos a manos de la investigación positivista.

En este contexto, Ian Shaw escribe La evaluación cualitativa, presentando una excelente introducción práctica a las estrategias y métodos de la evaluación cualitativa. Realiza un interesante análisis de las principales teorías en torno a la investigación educativa de corte cualitativo, dentro de las que destacan, entre otras, las trabajadas por: Donald Campbell (investigación por causas), Lee Cronbach (evaluación dentro de los programas), Robert Stake (investigación con estudio de casos), Elliot Eisner (evaluación reflexiva) y Egon Guba e Yvonna Lincoln (evaluación constructivista). 
Además de este interesante análisis, Shaw presenta una amplia gama de temas: los fundamentos de la evaluación y sus tendencias actuales; los principales teóricos de la evaluación; la evaluación de programas, de políticas y de práctica profesional; el diseño, la recolección de datos y el análisis de la evaluación. El autor complementa cada capítulo, con ejemplos de aplicación que ilustran los enfoques y los métodos utilizados en cada caso.

\section{VALORACIÓN CRÍTICA}

Dentro de los principales aciertos del libro, Shaw nos ofrece la primera demostración coherente de cómo utilizar los planteamientos cualitativos en la práctica evaluadora, con la finalidad de superar las limitaciones de los enfoques cuantitativos más tradicionales. Complementa el análisis de los planteamientos cualitativos a través de numerosos ejemplos que ayudan al lector a llevar a la práctica la evaluación cualitativa.

La evaluación cualitativa constituye, pues, una magnífica introducción a la investigación cualitativa para estudiantes, investigadores y educadores, preocupados por la fundamentación de los criterios metodológicos para la investigación educativa.

Sara Elvira Galbán Lozano 